\title{
Treatment of obesity and diabetes with bariatric surgery
}

\author{
Kevin A. Whitlock ${ }^{1}$, Richdeep S. Gill ${ }^{2}$, Noah Switzer ${ }^{1}$, Daniel W. Birch ${ }^{3}$ and Shahzeer Karmali ${ }^{2,3^{*}}$ \\ *Correspondence: shahzeer@ualberta.ca \\ ${ }^{1}$ Faculty of Medicine \& Dentistry, University of Alberta, Edmonton, Alberta, Canada. \\ ${ }^{2}$ Department of Surgery, University of Alberta, Edmonton, Alberta, Canada. \\ ${ }^{3}$ Center for the Advancement of Minimally Invasive Surgery (CAMIS), Royal Alexandria Hospital, Edmonton, Alberta, Canada.
}

\begin{abstract}
Obesity rates are on the rise worldwide. Nearly 1 in every 4 Canadians is classified as being overweight. With an increase in obesity, there is also a correlated rise in its comorbidities, most notably Type-2 Diabetes Mellitus (T2DM). Bariatric surgery is superior to diet and lifestyle management in managing the severe obese. These bariatric procedures are traditionally classified as either being restrictive(reducing caloric intake), or malabsorptive (re-routing the gastrointestinal tract). The roux-en-Y gastric bypass (RYGB) is the most commonly performed bariatric surgery. Studies have shown that post-RYGB, there is a significant improvement or even complete resolution in patients' type-2 diabetes mellitus (T2DM), with significantly more patients achieving euglycemia compared to the control population. RYGB has also been shown to prevent the development of T2DM. When RYGB was compared to more restrictive procedures, it achieved superior results in both weight-loss and T2DM resolution and the maintenance of these results long-term. The superiority of procedures, such as RYGB, is potentially explained through alterations in gut hormones, ghrelin and GLP-1. In this review, we explore the role of bariatric surgery in the prevention and treatment of T2DM, with a specific focus on the recent evidence surrounding surgical treatment via RYGB.
\end{abstract}

Keywords: Bariatric surgery, obesity, diabetes

\section{Introduction}

Over the past 30 years average body mass index (BMI) has been increasing worldwide [1]. More than $20 \%$ of the world's population is currently overweight and the prevalence of obesity has now exceeded 10\% [2]. The World Health Organization (WHO) estimates that 1.5 billion people are overweight and 500 million are clinically obese worldwide [3]. Unfortunately, in the next 20 years it is estimated that there will be 2.16 billion overweight and 1.12 billion obese individuals [2]. Canada is no exception to the global trend; as approximately $60 \%$ of the population is currently overweight [4]. As well, $24.1 \%$ of Canadians are classified as being clinically obese [5]. With the increasing BMI many people are at risk of developing obesityrelated comorbidities.

Type-2 Diabetes mellitus (T2DM) is an obesity-related comorbidity that results in progressive damage to numerous organ systems. An estimated 220 million people worldwide have been diagnosed with T2DM [6]. As of 2007, there were over 2 million Canadians (prevalence of 6.2\%) with T2DM [7]. Not surprisingly, the increasing prevalence of T2DM is correlated with the increasing prevalence of obesity $[8,9]$. This review will explore the role of bariatric surgery in the prevention and treatment of T2DM, with a specific focus on the recent evidence surroundingsurgical treatment via roux-en-Y gastric bypass (RYGB).

\section{Bariatric surgical procedures}

The current Canadian recommendation suggest that patients are eligible for bariatric surgery if they have a BMI $>40$ or a BMI $\geq 35 \mathrm{~kg} / \mathrm{m}^{2}$ with obesity- related comorbidities [10]. Bariatric surgery is considered to be a crucial part of an overall weight management strategy.Bariatric surgery is the only approach with substantial evidence supporting significant and sustainable weight loss in severely obese patients [11]. There are a variety of obesity surgeries currently being performed. The two classic categories are restrictive and malabsorptive procedures.

Laparoscopic adjustable gastric banding (LAGB), vertical banded gastroplasty (VBG), and laparoscopic sleeve gastrectomy (LSG)are commonly performed restrictive techniques. LAGB restricts food intake by having a physical band constricting the fundus of the stomach. This helps to decrease caloric intake by restricting food entry into the stomach.VBG involves creation of a small gastric pouch with staples and restriction of the outlet with banding. Unlike the LSG procedure, the VBG does not resect a portion of the stomach. LSG involves a surgical resection of the majority of the stomach, leaving a pouch that is approximately $15 \%$ of the stomach's original size. This procedure significantly and irreversibly restricts the capacity of the stomach. However, it is important to note that the classic grouping of LSG is likely not accurate. Physiologically, LSG is probably more similar to the bypass procedure.

There are a select number of bariatric surgery procedures that combine elements of calorie restriction and malabsorption. Biliopancreatic diversion with duodenal switch (BPD-DS) and roux-en-Y gastric bypass (RYGB) are the two majormalabsorptive procedures. BPD-DS is a combination of a sleeve gastrectomy and a bypass of a portion of the small bowel. The stomach is reduced in size and the outlet of the stomach is reattached to 
Whitlock et al. Global Epidemic Obesity 2013,

about $50 \mathrm{~cm}$ from the ileocecal valve. This allows food from the stomach to bypass the majority of the small bowel. Similarly, the RYGB procedure involves creation of a small gastric pouch that is reconnected to the proximal jejunum. Less small bowel is bypassed with the RYGB procedure. Currently, RYGB is the most commonly performed malabsorptive procedure. As well, research suggests that malabsorptive procedures are more effective than restrictive with respect to weight loss [12].

\section{Bariatric surgery and medical therapy for T2DM}

A substantial systematic review by Buchwald et al., reported that RYGB is able to achieve significant weight loss and superior resolutions rates for T2DM [11]. Recent studies have supported the evidence presented in thisreview and it appears that RYGB may be more effective than conventional medical therapy in terms of weight loss and T2DM resolution.

Dixon et al., published a review of numerous studies that compared bariatric surgery to conventional medical treatment for T2DM [13]. Based on the studies they reviewed, bariatric surgery was superior to medical treatment for improving outcomes related toT2DM. The highest quality study they identified was by Sjostrom et al., in 2004 [14]. This prospective case-control study compared 2010 surgically treated obese patients to 2037 obese medically treated control subjects. Three types of bariatric surgical procedures were used, including: RYGB, VBG, and LAGB. After 2 years, mean weight values had increased by $0.1 \%$ in the control group and decreased by $23.4 \%$ in the surgical group. At the same time point, significantly more control subjects had developed T2DM when compared to the surgical group (8\% versus $1 \%$ ). Furthermore, after 10 years of follow-up the control group experienced a mean weight increase of $1.6 \%$ versus a mean weight decrease of $25 \%$ for RYGB, $16 \%$ for VBG, and $13 \%$ for LAGB. Thus, the surgically treated patients had superior weight loss at 10 years and the RYGB group had the statistically greatest long-term weight loss. Additionally, the incidence of T2DM increased to $24 \%$ for the control group, which was significantly greater than the $7 \%$ incidence in the surgical group. Therefore, the odds of developing T2DM were four times greater for medically treated obese patients in comparison to surgically treated obese patients. Overall, this study supports the effectiveness of bariatric surgery for not only weight loss but also preventing the development of T2DM.

A recent randomized trial by Schauer et al., compared bariatric surgery to conventional medical therapy with the major outcome being improvement in T2DM [15]. A total of 150 patients were divided evenly into a medical therapy, RYGB, and LSG groups. Preoperative BMI was statistically similar among the groups; being around $37 \mathrm{~kg} / \mathrm{m}^{2}$ for each. All patients had uncontrolled T2DM, with $44 \%$ of the patients in each group using insulin. All preoperative characteristics were similar, including: smokers, hypertension, dislipidemia, race, age, and sex. After 12 months, outcomes were analyzed for each group. The RYGB group achieved a significantly lower
BMI $\left(26.8 \mathrm{~kg} / \mathrm{m}^{2}\right)$ when compared to both the LSG $\left(27.2 \mathrm{~kg} / \mathrm{m}^{2}\right)$ and medical therapy groups $\left(34.4 \mathrm{~kg} / \mathrm{m}^{2}\right)$. Schauer et al., then used an $\mathrm{A} 1 \mathrm{c}$ value of $6.0 \%$ as their target for T2DM and glycemic control outcomes. The surgical groups had significantly more patients reach the A1c target of $6.0 \%$ (42\% for RYGB, 37\% for LSG) in comparison to the medical therapy group (12\%) [15]. However, there was no difference between the RYGB and LSG groups with respect to the A1c target. Yet, Schauer et al., mention that $28 \%$ of the LSG patients who reached the A1c target did so with the help of medications versus $0 \%$ of the RYGB patients. Additionally, at 12 months $78 \%$ of RYGB patients stopped all Diabetes medications versus $51 \%$ of the LSG patients and $0 \%$ of the medical therapy patients. Fasting glucose was also significantly lower in the surgical groups (5.5 $\mathrm{mmol} / \mathrm{L}$ for RYGB and $5.4 \mathrm{mmol} / \mathrm{L}$ for LSG) when compared to the medical therapy group $(6.7 \mathrm{mmol} / \mathrm{L})$. The limitations of this study was the short follow-up time and the fact that $9(18 \%)$ of the medical therapy patients did not follow-up [15]. However, the use of well-defined lab measurements for monitoring T2DM outcomes is commendable.

In another randomized trial, Mingrone et al., also compared bariatric surgery to conventional medical therapy [16]. Their primary outcome was the rate of Diabetes remission. They randomized 60 patients to a medical therapy, RYGB, and biliopancreatic diversion (BPD) group. All their patients had at least 6 years of diagnosed T2DM with an average BMI around $45 \mathrm{~kg} / \mathrm{m}^{2}$. Baseline fasting glucose and $A 1 \mathrm{c}$ values were measured to be followed as the primary outcome. There was no significant difference among the groups with respect to either of these parameters. As well, the surgical patients had to discontinue all pharmacologic treatments within 15 days postoperatively. The only preoperative characteristic that differed among the groups was the lipid profile. The RYGB group had significantly lower low-density lipoprotein and total cholesterol levels when compared to the medical therapy and BPD groups.After two years, both surgical groups had significantly lower mean BMIs (RYGB 29.3 and BPD $29.2 \mathrm{~kg} / \mathrm{m}^{2}$ ) when compared to the medical therapy group $\left(43.1 \mathrm{~kg} / \mathrm{m}^{2}\right)$ [16]. At the same time point, $0 \%$ of the medical therapy patients, $75 \%$ of the RYGB patients, and $95 \%$ of the BPD patients had remission of their T2DM. Additionally, with respect to the fasting glucose and A1c values, Mingrone et al., performed a Kaplan-Meier analysis to compare the average time to normalization. They found that BPD patients (4 months) had significantly faster average time to normalization when compared to the RYGB patients (10 months). As well, both surgical groups had significantly better fasting glucose and A1c values when compared to the medical therapy group at two years postoperative. The only drawbacks with the study by Mingrone et al., were the small number of patients in each group and the difference in the preoperative lipid profile. However, their results support the effectiveness of not only bariatric surgery in comparison to medical therapy; but also the effectiveness of the two common bariatric surgical 
Whitlock et al. Global Epidemic Obesity 2013,

procedures (RYGB and BPD).

\section{Malabsorptive versus restrictive procedures}

LAGB is a commonly performed procedure because it does not require surgically altering the stomach or small bowel. This procedure is relatively quicker to perform and very popular in the private sector, but it may not be as effective as RYGB in terms of weight loss and T2DM resolution.A recent retrospective study by Boza et al., also compared LAGB to RYGB [17]. 91 RYGB patients were compared to 62 LAGB patients. The mean preoperative BMI was $39.6 \mathrm{~kg} / \mathrm{m}^{2}$ in the RYGB and $35.8 \mathrm{~kg} / \mathrm{m}^{2}$ in the LAGB. As well, $5.5 \%$ of the RYGB patients and $6.4 \%$ of the LAGB patients had T2DM prior to surgery. These rates are relatively low compared to many other metabolic surgery studies, but may reflect surgical patient selection practices at their institution. After 5 years of follow-up, the excess weight loss was significantly higher in the RYGB group when compared to the LAGB group (92.9\% versus $59.1 \%)$. As well, T2DM resolved or improved in $80 \%$ of the RYGB patients in comparison to only $25 \%$ of the LAGB patients. Therefore, this study supports the superiority of RYGB with respect to both weight loss and T2DM resolution.

A prospective two-cohort pair-matched study by Campos et al., compared 100 LAGB patients to 100 RYGB patients [18]. Preoperatively the mean BMI was $45.7 \mathrm{~kg} / \mathrm{m}^{2}$ in the LAGB group and $46.0 \mathrm{~kg} / \mathrm{m}^{2}$ in the RYGB. As well, the rate of T2DM was 34\% in each group prior to bariatric surgery. 1 year postoperatively the remission rates for T2DM were analyzed. Campos et al., found that significantly more diabetic patients in the RYGB had resolution of their T2DM when compared to the LAGB patients ( $76 \%$ versus $50 \%$ ). As well, patients in the RYGB group had significantly lower mean BMI at 1 year postoperative ( $30 \mathrm{~kg} / \mathrm{m}^{2}$ versus $36 \mathrm{~kg} / \mathrm{m}^{2}$ in the LAGB group). Furthermore Campos et al., suggested greater excess weight loss may explain the superior resolution rate for T2DM in the RYGB group compared to the LAGB group (odds ratio 0.95). However, this was only an association and there are likely many unaccounted factors that influence T2DM resolution in addition to weight loss.

Recently, Romy et al., reported a retrospective matchedpair study that compared LAGB to RYGB [19]. A total of 442 patients were included in the study with an even split between LAGB and RYGB. Romy et al., chose to exclude patients with a BMI $>50 \mathrm{~kg} / \mathrm{m}^{2}$ and those who were operated early on in their program to minimize the effects of a learning curve. When weight loss was analyzed they found that RYGB achieved a significantly higher maximal excess weight loss when compared to LAGB (78.5\% versus $64.8 \%$ ). Furthermore, $92.3 \%$ of their patients presented for follow-up after 6 years postoperative. At this time significantly more patients had a BMI $>40 \mathrm{~kg} / \mathrm{m}^{2}$ in the LAGB group in comparison to the RYGB group (13.8\% versus $2.4 \%$ ). Therefore, if the notion that weight loss were associated with resolution of T2DM one would expect their RYGB patients to have superior resolution rates. The mean fasting glucose was significantly lower in the RYGB group after 3 years (4.97 versus $5.15 \mathrm{mmol} / \mathrm{L}$ ).

\section{RYGB and long-term T2DM resolution}

A retrospective cohort study by DiGiorgi et al., challenged the effectiveness of RYGB surgery with respect to improving T2DM in obese patients [20]. Their study included 42 T2DM patients who underwent RYGB surgery at their institution. The mean preoperative BMI was higher than many studies as it was 51.4 $\mathrm{kg} / \mathrm{m}^{2}$. The mean preoperative plasma glucose value was 9.3 $\mathrm{mmol} / \mathrm{L}$ and $89 \%$ of their patients required insulin or other oral medications to control their T2DM. After a mean follow up of 5 years, $64 \%$ of their patients had complete resolution of their T2DM. 36\% were considered to have improved T2DM, meaning their lab values improved or they required less medication. The mean plasma glucose value at 5 years had improved to $6.2 \mathrm{mmol} / \mathrm{L}$. Interestingly though $24 \%$ of their patients had worsening or recurrence of their T2DM. Worsening was defined as an increase in medication after a period of improvement and recurrence was defined as an elevated A1C $(>6.0 \%)$ or fasting glucose $(>6.9 \mathrm{mmol} / \mathrm{L})$ after a documented period of resolution. DiGiorgi et al., went on to compare diabetic subjects who improved to the diabetic subjects who worsened after RYGB surgery [20]. Most striking was the fact that diabetic subjects who worsened had significantly higher percent weight regain when compared to diabetic subjects who improved (37.7\% versus $15.4 \%$ ). Consequently, DiGiorgi et al., argue that patients with increased weight regain after RYGB surgery are more likely to experience T2DM worsening or recurrence. Additionally, DiGiorgi et al., also analyzed the resolution rate for T2DM with respect to preoperative T2DM control. They found that all of the diet controlled patients experienced resolution. $85 \%$ of the oral medication controlled Diabetes experienced resolution and only $8 \%$ of the insulin controlled diabetic patients experienced T2DM resolution. Therefore, the preoperative control and by extension severity of a patient's T2DM is likely predictive of whether they will improve or completely resolve their Diabetes.

A recent retrospective study by Obeid et al., challenged the conclusions made by DiGiorgi et al., with respect to the longterm outcomes of RYGB surgery [21]. Their study included 770 patients of which 172 presented for long-term follow up. In the preoperative period, their patients had a median BMl of $46 \mathrm{~kg} /$ $\mathrm{m}^{2}$ and $45 \%$ had diagnosed T2DM. After a median follow-up of 12 months, the median BMI had decreased to $28.4 \mathrm{~kg} / \mathrm{m}^{2}$. As well, $94 \%$ of diabetic patients had complete resolution and $3 \%$ had improvement of their T2DM. Improvement was defined as a decrease in symptoms, a decrease in medications, or an improvement in lab values. Obeid et al., reported that after a median follow-up of 75 months, the median BMI was $29.6 \mathrm{~kg} /$ $\mathrm{m}^{2}$ [21]. This was a statistically significant weight regain when compared to the short-term follow-up reported. However, the patients did not reach the obese category for BMI. The rate of resolution of T2DM dropped to $82 \%$ after long-term follow- 
Whitlock et al. Global Epidemic Obesity 2013,

up; however the rate of improvement in T2DM increased to $13 \%$. Obeid et al., discussed their tremendous resolution rate of T2DM. They acknowledged that only a select number of studies have reported T2DM resolution rates similar to theirs $[17,19,22]$. However, Obeid et al., argue that there is evidence in the literature for a relationship between the maintenance of weight loss and remission of comorbidites, such as T2DM [23]. Consequently, they believe that their long-term maintenance of weight loss (BMI $29.6 \mathrm{~kg} / \mathrm{m}^{2}$ at 75 months) may be responsible for the excellent resolution rate of T2DM [21].

There are some issues with the Obeid et al., study. Firstly, only 172 patients were included out of a possible total of 770 [21]. The rationale was 78\% of those patients did not present for long-term follow-up and were excluded as a result. Understandably, their study wanted to focus on long-term outcomes; however it was not clear why these particular patients followed-up and others did not. As well, their median preoperative BMl was $46 \mathrm{~kg} / \mathrm{m}^{2}$, which is undoubtedly excluding some of the higher risk and higher BMI patients that would be operated on in a publically funded system. Nonetheless, Obeid et al., support the effectiveness of laparoscopic RYGB surgery as not only a weight loss surgery, but also a treatment for T2DM.

A recent retrospective review by Higa et al., also reported long-term outcomes for RYGB surgery [22]. Their study included 242 patients with the majority of patients having a BMI between $40-50 \mathrm{~kg} / \mathrm{m}^{2}$. Before undergoing surgery, the rate of T2DM was $19 \%$ among all the patients. After 10 years, $21 \%$ of the patients followed-up with their clinic. Higa et al., found that the average BMI had dropped to $33.2 \mathrm{~kg} /$ $\mathrm{m}^{2}$. Of the diabetic patients who presented to clinic, $67 \%$ experienced improvement or total resolution of their T2DM. Consequently, there is accumulating evidence that RYGB surgery may achieve long-term T2DM resolution, as long as weight regain is minimized in the late postoperative period.

\section{Potential mechanisms for RYGB-related T2DM improvement}

The traditional rationale postulated that calorie restriction or malabsorption were the primary mechanisms by which patients lost weight after bariatric surgery $[\mathbf{2 4}, \mathbf{2 5}]$. However, the mechanisms related to improving T2DM are likely more complex than just decreased caloric intake. For instance, alteration of gut hormones through bariatric surgery may influence the action or secretion of insulin [26]. In turn T2DM may improve by having a more antidiabetic balance of hormones.

We recommend a recent review by Stefater et al., which provides an extensive discussion on the current understanding of the mechanisms of RYGB, LAGB, and LSG [27]. Interstingly, they propose that current evidence shows LSG to be more similar in action to RYGB, rather than LAGB. They cite changes in hormones like Leptin and Ghrelin; as well as changes in food intake and glucose regulation that are similar between LSG and RYGB. Stefater et al., also acknowledge that the current evidence is still lacking with regards to mechanism of action for LSG, LAGB, and RYGB.

Only a select few studies have speculated as to the mechanism RYGB surgery is able to alter hormone balance in the body. For instance, the hindgut theory postulates that rapid transit of undigested into the small bowel triggers the upregulation of the hormone GLP-1. GLP-1 is thought stimulate insulin secretion and protect $\beta$-cells [28]. However, other mechanisms are likely involved as T2DM patients have been known to discontinue all diabetic medications before significant weight loss had occurred after bariatric surgery $[29,30]$.

The hormone ghrelin is thought to be diabetogenic and its levels have been shown to decrease following RYGB surgery [31]. Consequently, the antagonism of insulin secretion by ghrelin is thought to decrease following RYGB [32]. Though a detailed discussion of the mechanism of T2DM improvement following RYGB is beyond the scope of this review, we suggest the excellent review by Cummings et al., [26].

\section{Conclusion}

T2DM is becoming more prevalent not only in Canada, but throughout the world. There is substantial research supporting the association between T2DM and obesity. Based on this association, weight loss has been proposed as a treatment strategy for T2DM. Bariatric surgery is considered to be the only evidence-basedstrategy to obtain significant and sustained weight loss for obese individuals. Not surprisingly, bariatric surgery has been shown to be effective at treating T2DM as well. However, there is still controversy over which bariatric surgical procedure is superior for T2DM in obese patients. Nevertheless, there is robust evidence that T2DM is either improved or resolved after procedures like RYGB. Continued research is needed to determine the most effective procedure for specific patients and the mechanism by which bariatric surgery improves T2DM in obese patients.

\section{Competing interests}

The authors declare that they have no competing interests.

\section{Publication history}

Editor: Nestor F. de la Cruz-Muñoz, University of Miami Miller School of Medicine, USA.

Received: 28-Feb-2013 Revised: 08-Apr-2013

Accepted: 13-Apr-2013 Published: 15-Apr-2013

\section{References}

1. Finucane MM, Stevens GA, Cowan MJ, Danaei G, Lin JK, Paciorek CJ, Singh GM, Gutierrez HR, Lu Y, Bahalim AN, Farzadfar F, Riley LM and Ezzati $\mathrm{M}$ : National, regional, and global trends in body-mass index since 1980: systematic analysis of health examination surveys and epidemiological studies with 960 country-years and 9.1 million participants. Lancet 2011, 377:557-67. | Article | PubMed

2. Kelly T, Yang W, Chen CS, Reynolds K and He J: Global burden of obesity in 2005 and projections to 2030. Int J Obes (Lond) 2008, 32:1431-7. | Article I PubMed 
Whitlock et al. Global Epidemic Obesity 2013,

3. WHO. Obesity and overweight: Fact sheet 311, 2011.

4. Tjepkema M: Adult obesity in canada: Measured height and weight. Nutrition: Findings from the Canadian Community Health Survey. 2005(1). I Pdf

5. Statistics Canada: Canadian health measures survey: Adult obesity prevalence in canada and the united states. Accessed May 10, 2011. Website

6. WHO. Diabetes: Fact sheet 312, 2011.

7. Public Health Agency of Canada. Report from the national diabetes surveillance system: Diabetes in canada, 2009.. Updated 2009. Website

8. Mokdad AH, Ford ES, Bowman BA, Nelson DE, Engelgau MM, Vinicor F and Marks JS: Diabetes trends in the U.S.: 1990-1998. Diabetes Care 2000, 23:1278-83. | Article | PubMed

9. Must A, Spadano J, Coakley EH, Field AE, Colditz G and Dietz WH: The disease burden associated with overweight and obesity. JAMA 1999, 282:1523-9. | Article | PubMed

10. Lau DC, Douketis JD, Morrison KM, Hramiak IM, Sharma AM and Ur E: 2006 Canadian clinical practice guidelines on the management and prevention of obesity in adults and children [summary]. CMAJ 2007, 176:S1-13. | Article | PubMed Abstract | PubMed Full Text

11. Buchwald $H$, Avidor $Y$, Braunwald $E$, Jensen MD, Pories $W$, Fahrbach $K$ and Schoelles K: Bariatric surgery: a systematic review and meta-analysis. JAMA 2004, 292:1724-37. | Article | PubMed

12. Picot J, Jones J, Colquitt JL, Gospodarevskaya E, Loveman E, Baxter L and Clegg AJ: The clinical effectiveness and cost-effectiveness of bariatric (weight loss) surgery for obesity: a systematic review and economic evaluation. Health Technol Assess 2009, 13:1-190. | Article | PubMed

13. Dixon JB, le Roux CW, Rubino F and Zimmet P: Bariatric surgery for type 2 diabetes. Lancet 2012, 379:2300-11. | Article | PubMed

14. Sjostrom L, Lindroos AK, Peltonen M, Torgerson J, Bouchard C, Carlsson B, Dahlgren S, Larsson B, Narbro K, Sjostrom CD, Sullivan M and Wedel $\mathrm{H}$ : Lifestyle, diabetes, and cardiovascular risk factors $\mathbf{1 0}$ years after bariatric surgery. N Engl J Med 2004, 351:2683-93. | Article | PubMed

15. Schauer PR, Kashyap SR, Wolski K, Brethauer SA, Kirwan JP, Pothier CE, Thomas S, Abood B, Nissen SE and Bhatt DL: Bariatric surgery versus intensive medical therapy in obese patients with diabetes. $N$ Engl J Med 2012, 366:1567-76. | Article | PubMed Abstract | PubMed Full Text

16. Mingrone G, Panunzi S, De Gaetano A, Guidone C, laconelli A, Leccesi L, Nanni G, Pomp A, Castagneto M, Ghirlanda G and Rubino F: Bariatric surgery versus conventional medical therapy for type 2 diabetes. $N$ Engl J Med 2012, 366:1577-85. | Article | PubMed

17. Boza C, Gamboa C, Awruch D, Perez G, Escalona A and Ibanez L: Laparoscopic Roux-en-Y gastric bypass versus laparoscopic adjustable gastric banding: five years of follow-up. Surg Obes Relat Dis 2010, 6:470-5. | Article | PubMed

18. Campos GM, Rabl C, Roll GR, Peeva S, Prado K, Smith J and Vittinghoff $\mathrm{E}$ : Better weight loss, resolution of diabetes, and quality of life for laparoscopic gastric bypass vs banding: results of a 2-cohort pairmatched study. Arch Surg 2011, 146:149-55. | Article I PubMed

19. Romy S, Donadini A, Giusti V and Suter M: Roux-en-Y gastric bypass vs gastric banding for morbid obesity: a case-matched study of $\mathbf{4 4 2}$ patients. Arch Surg 2012, 147:460-6. I Article I PubMed

20. DiGiorgi M, Rosen DJ, Choi JJ, Milone L, Schrope B, Olivero-Rivera L, Restuccia N, Yuen S, Fisk M, Inabnet WB and Bessler M: Re-emergence of diabetes after gastric bypass in patients with mid- to long-term follow-up. Surg Obes Relat Dis 2010, 6:249-53. | Article | PubMed

21. Obeid A, Long J, Kakade M, Clements RH, Stahl R and Grams J: Laparoscopic Roux-en-Y gastric bypass: long term clinical outcomes. Surg Endosc 2012, 26:3515-20. | Article | PubMed

22. Higa K, Ho T, Tercero F, Yunus T and Boone KB: Laparoscopic Roux-en-Y gastric bypass: 10-year follow-up. Surg Obes Relat Dis 2011, 7:516-25. Article | PubMed

23. Sugerman HJ, Wolfe LG, Sica DA and Clore JN: Diabetes and hypertension in severe obesity and effects of gastric bypass-induced weight loss. Ann Surg 2003, 237:751-6. | Article | PubMed Abstract |
PubMed Full Text

24. Trostler N, Mann A, Zilberbush N, Avinoach E and Charuzi II: Weight Loss and Food Intake 18 Months following Vertical Banded Gastroplasty or Gastric Bypass for Severe Obesity. Obes Surg 1995, 5:39-51. | Article | PubMed

25. Halmi KA, Mason E, Falk JR and Stunkard A: Appetitive behavior after gastric bypass for obesity. Int J Obes 1981, 5:457-64. | Article | PubMed

26. Cummings DE, Overduin J, Shannon MH and Foster-Schubert KE: Hormonal mechanisms of weight loss and diabetes resolution after bariatric surgery. Surg Obes Relat Dis 2005, 1:358-68. | Article | PubMed

27. Stefater MA, Wilson-Perez HE, Chambers AP, Sandoval DA and Seeley RJ: All bariatric surgeries are not created equal: insights from mechanistic comparisons. Endocr Rev 2012, 33:595-622. | Article | PubMed

28. Drucker DJ: Glucagon-like peptide-1 and the islet beta-cell: augmentation of cell proliferation and inhibition of apoptosis. Endocrinology 2003, 144:5145-8. | Article | PubMed

29. Schauer PR, Burguera B, Ikramuddin S, Cottam D, Gourash W, Hamad G, Eid GM, Mattar S, Ramanathan R, Barinas-Mitchel E, Rao RH, Kuller L and Kelley D: Effect of laparoscopic Roux-en Y gastric bypass on type 2 diabetes mellitus. Ann Surg 2003, 238:467-84; discussion 84-5. | Article | PubMed Abstract | PubMed Full Text

30. Pories WJ: Diabetes: the evolution of a new paradigm. Ann Surg 2004, 239:12-3. | Article | PubMed Abstract | PubMed Full Text

31. Cummings DE and Shannon $\mathrm{MH}$ : Roles for ghrelin in the regulation of appetite and body weight. Arch Surg 2003, 138:389-96. | Article | PubMed

32. Broglio F, Arvat E, Benso A, Gottero C, Muccioli G, Papotti M, van der Lely AJ, Deghenghi R and Ghigo E: Ghrelin, a natural GH secretagogue produced by the stomach, induces hyperglycemia and reduces insulin secretion in humans. J Clin Endocrinol Metab 2001, 86:5083-6. | Article I PubMed

\section{Citation:}

Whitlock K A, Gill R S, Switzers N, Birch D W and Karmali S: Treatment of obesity and diabetes with bariatric surgery. Global Epidemic Obesity 2013, 1:1. http://dx.doi.org/10.7243/2052-5966-1-1 